\title{
AS DESAVENTURAS DA DEMOCRACIA - UM OLHAR CRÍTICO SOBRE BREXIT, LE PEN E TRUMP
}

\author{
Marta Nunes da Costa ${ }^{1}$
}

\section{Resumo:}

A democracia está em crise e ninguém parece contestar esse fato. O problema que se levanta é de que forma agir diante dos vários acontecimentos políticos que parecem ter marcado uma tendência no paradigma democrático do Ocidente. Este artigo oferece uma leitura possível para compreender a nossa condição presente a partir de um olhar crítico sobre as os resultados políticos do Brexit, a ascenção de Le Pen e a vitória de Trump nas últimas eleições presidenciais.

Palavras-chave: Democracia. Ocidente. Trump. Brexit. Le Pen.

\section{THE MISADVENTURES OF DEMOCRACY - A CRITICAL LOOK ON BREXIT, LE PEN AND TRUMP}

\begin{abstract}
:
Democracy is (in) crisis and nobody seems to contest this fact. The problem one confronts today is: how should one act when confronted with several political events that are shaping a new trend in the occidental democratic paradigm? This article offers a possible reading to understand our present condition, as well as a critical glance upon the political results of Brexit, Le Pen's rise and Trump's victory in the last presidential elections.
\end{abstract}

Keywords: Democracy. Occident. Trump. Brexit. Le Pen.

\section{O contexto}

O mundo mudou, mas a mudança que observamos não é de hoje. Ao contrário de muitos que ficaram surpresos com Brexit, a vitória de Trump ou a ascensão do populismo em geral, mais particularmente na Europa, a minha surpresa foi motivada provavelmente pelas razões opostas da maioria. As questões devem ser reformuladas - a real questão não é 'Como é que o Reino Unido vota abandonar a Europa?', ou

\footnotetext{
${ }^{1}$ Professora Adjunta de Filosofia, Universidade Federal do Mato Grosso do Sul. Doutorada em Ciência Política e Filosofia pela New School for Social Research (2006). E- mail: nunesdacosta77@gmail.com
} 
‘Como é possível Trump ter ganho as eleições?' mas sim, como é possível o projeto europeu ter durado tanto no seu movimento de integração e expansão continuas? e, como levou tanto tempo a que um 'Trump' aparecesse nos Estados Unidos da América? Explico-me.

Digo muitas vezes que o que mais me surpreende é a capacidade do ser humano se auto-destruir. Os modos de auto-destruição são diversos: vão desde as drogas, ao modo de vida, às escolhas políticas e à memória, ou neste caso, à falta dela. O ser humano parece ter uma disposição fantástica para a perda de memória individual e coletiva; a sua memória é seletiva, mas no mau sentido. Ele guarda as 'boas memórias', inclusive criando memórias do zero (sem que estas sejam baseadas em 'fatos') e esquece as más memórias, aquelas que incomodam ou que obrigam a um questionamento moral, ou, pior, aquelas que obrigam a um posicionamento real, prático, no mundo. Olhando para a história do último século deveríamos ser obrigados a reconhecer a importância do que herdámos: por um lado, uma herança de genocídio e morte, com 100 milhões de vidas sacrificadas por visões do mundo de certos líderes políticos; por outro lado, uma herança de superação e reconstrução de morte, a partir da adoção consciente de um projeto político alternativo, capaz de promover e garantir a paz entre os indivíduos e entre os povos. Deste último nasceu a Europa, essa expressão que remete a um velho continente e que tudo e nada quer dizer; a Europa que sempre esteve suspensa entre aquilo que é (e o que é, sempre foi guerra) e aquilo que pode e deseja ser, a saber, um mundo possível moldado por respeito mútuo e equilíbrio de poderes. Dessa Europa, da qual o leitor saberá a história, foram reavivadas revoluções democráticas e foi projetado um horizonte comum que poderia ser retraçado à Revolução Francesa e até à Revolução Americana. Este horizonte comum ainda nos define hoje, com os seus ideais de liberdade, igualdade e fraternidade. Deste ou daquele lado do Atlântico constrói-se um sujeito histórico movido por um novo ímpeto: o Ocidente e a democracia. O Ocidente, que aponta para a morte, procura pela democracia manter-se vivo e quiçá, conquistar o Oriente, fonte de vida. ${ }^{2}$ Essa conquista deve ser progressiva, de preferência pacífica, por meios que respeitem os ideais fundadores dos quais partem; por outras palavras, o Ocidente que

\begin{tabular}{|c|c|c|c|c|}
\hline \multicolumn{5}{|c|}{ 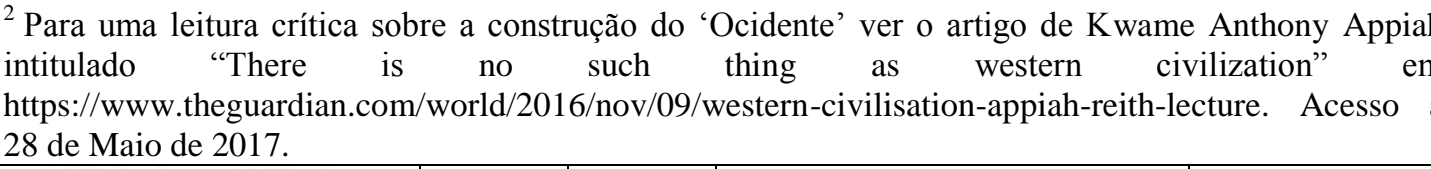 } \\
\hline Ronita Dialectus & Ano 4 & n. 11 & Agosto - Dezembro 2017 & p. $264-279$ \\
\hline
\end{tabular}


abraçou uma política laica deve conquistar o mundo sem recorrer aos deuses ou às crenças, mas antes, recorrendo apenas às suas virtudes, sejam estas intrínsecas ou conscientemente construídas. Neste horizonte de liberdade exemplar, pelo menos na teoria, o mercado tornou-se o meio privilegiado para a sua expansão: o capitalismo, pela sua natureza sempre expansiva e global, oferece as redes conceituais a partir do qual todos os ideais - de 'nós' e 'deles' - devem ser sujeitos.

Se os anos de 1950 foram os anos dourados nos Estados Unidos, só nos anos 70 na Europa se dá a vaga de democratizações: Portugal, Espanha, Itália, todos filhos de ditadores, têm de aprender os sentidos e práticas de liberdade. Reino Unido, com a sua história de conflito e resolução, parece sempre estar um passo à frente; França, o coração da Europa, representa o passado com tudo o que já não queremos, a saber, as hierarquias, a Igreja, a moral transcendente; e o futuro para onde queremos dirigirnos: o futuro da igualdade, da liberdade e da fraternidade, o futuro onde os valores morais e políticos convergem na virtude da cidadania e onde cada um de nós está irremediavelmente preso à sua própria condição: a imanência.

Ao mesmo tempo que as novas democracias davam os primeiros passos na Europa, agora de forma concertada entre países, surge nos anos 80 uma nova proposta e teoria (política e) económica acerca de como pensar e dirigir o mercado. O neoliberalismo, de ideologia periférica quase-excluída torna-se progressivamente dominante e hegemónica. O capitalismo nesta nova fase ganha contornos mais brutais, evidenciando as suas contradições intrínsecas de forma flagrante: as conquistas por novos direitos políticos, sociais, culturais, sexuais, económicos, são acompanhadas pela fragmentação e isolamento de sujeitos e atores políticos. O simbólico é redefinido à luz da necessidade de gestão e disciplina dos corpos; as ideias são dirigidas de forma a reforçar aquilo que o modelo neoliberal diz; a liberdade é redefinida, radicalizando o entendimento contratualista tão denunciado por Marx e Engels de que agora só somos livres porque podemos comprar e vender, e porque nos podemos comprar e vender. O aprofundamento da lógica neoliberal onde se diz que o Estado deve ser 'mínimo' ao mesmo tempo que se torna ator cada vez mais importante enquanto facilitador do mercado, exacerba por outro lado as

\begin{tabular}{|l|l|l|l|l|}
\hline Q Rovista Dialectus & Ano 4 & n. 11 & Agosto - Dezembro 2017 & p. $264-279$ \\
\hline
\end{tabular}


contradições da democracia. Se a democracia é crise, como defendi noutro artigo ${ }^{3}$, a democracia capitalista é uma contradição dos termos destinada a falhar: por um lado, reclamamos uma igualdade que só existe se formos livres, e só seremos livres quando formos emancipados do domínio da necessidade; por outro lado, somos forçados a uma liberdade que se apresenta, desde o início, como 'não tendo escolha' lembremo-nos que Tatcher nos convence acerca das maravilhas do mercado dizendo 'There's no alternative'. E essa liberdade, para que seja exercida, requer, como sua condição necessária e de possibilidade, que a igualdade se desdobre na igualdade formal (de pessoas 'jurídicas') e na desigualdade real, em todos os outros campos. Afinal, se fossemos todos iguais e todos livres, ninguém teria de se sujeitar às 'leis do mercado', nem às leis 'da oferta e da procura' e o capitalismo morreria.

Conseguimos alcançar a proeza de viver por mais de trinta anos na total contradição entre teorias e práticas e, miraculosamente, construir as nossas próprias subjetividades no ambiente em que, ao mesmo tempo que incentiva a (re) invenção permanente de nós mesmos e conduz a uma fragmentação do eu, exige que permaneçamos 'unos' e substanciais.

A Europa cresceu neste ambiente. Como uma criança pequena que aprende a dar os primeiros passos, a Europa também aprende a andar no tempo definido pelos imperativos do capital e do mundo financeiro. Isso requer conciliar duas agendas totalmente distintas e em permanente oposição: a agenda que precisa garantir a sobrevivência das democracias, defendendo um certo ideal de 'estado de bem-estar social' e, por outro lado, a agenda que precisa erodir as democracias entendidas como soberanias (nação-estado), pois só realizará a sua promessa de agente histórico universal quando os particulares lhe estiverem subsumidos.

O conflito destas duas agendas foi gerenciado por bastante tempo; não resolvido, porque o conflito é irresolúvel, mas digamos que ao nível das aparências a Europa conseguiu projetar a possibilidade de uma nova ordem global, baseada em princípios universais, ou melhor dizendo, ocidentais. Com isso, e por que os princípios são universais apenas porque são ocidentais, depreende-se que o exemplo da paz e da prosperidade prometida quer pelos ideais, quer pelo modelo político

\footnotetext{
${ }^{3}$ Ver Nunes da Costa, Marta, “A Crise da Democracia”, em ROSAS, João Cardoso (Org.), Manual de Filosofia Política, Almedina, Coimbra, Portugal, 2013.

\begin{tabular}{|c|l|l|l|l|}
\hline Q Rovista Dialectus & Ano 4 & n. 11 & Agosto - Dezembro 2017 & p. $264-279$ \\
\hline
\end{tabular}
}


democrático, seria suficiente para contaminar o resto do mundo e assim, ocidentalizálos. O 'outro', ou os 'outros' tornar-se-iam, com o tempo, iguais aos 'eus'.

Enquanto o clima era de prosperidade todos os problemas pareciam suportáveis; porém, a crise do sub-prime de 2007/2008 desencadeada pelos Estados Unidos expôs todas as feridas e obrigou a um choque de realidade. Esta crise, que ainda respiramos, desvelou a impossibilidade de compatibilizar duas ordens incompatíveis: por um lado, a ordem do capitalismo, modo de produção onde a relação de troca é naturalizada, e por outro lado, a ordem da democracia, onde os valores não podem ser traduzidos nem reduzidos a 'preços'. Esta incompatibilidade manifesta-se em dois casos específicos: o caso das intervenções do FMI e da Troika (FMI, Banco Central Europeu e Comissão Europeia) e o caso dos refugiados. O primeiro, que, pela intervenção da Troika em vários países expõe de forma escancarada o modo instrumental como os dirigentes usam o discurso democrático para avançar agendas financeiras, contribuindo diretamente para o aumento do abismo entre os mais pobres e os mais ricos; o segundo, que pelo aumento da guerra civil na Síria mas também de vários outros países do Oriente médio e de África, confronta países europeus com 'outros' que dificilmente podem ser incorporados ou ocidentalizados tout court.

Quer o caso da intervenção da Troika, quer dos refugiados tem efeitos comuns: o efeito 'objetivo' prende-se com o agravamento do desemprego em cada país, já que a ideologia neoliberal obrigava a que todos os países intervencionados se sujeitassem a medidas de austeridade, o que significava, na prática, erradicar postos de trabalho e/ou reduzir salários. Estas medidas, sabemos hoje (aliás, sabíamos na época, mas só hoje o FMI está a aceitar o óbvio) são contra-produtivas, i.e., elas não geram crescimento económico, muito pelo contrário, elas agravam a situação já debilitada de qualquer país 'em crise'. Basta olhar para a Grécia ou Espanha, ambos com taxas de desemprego assustadoras entre os jovens (perto dos 50\%). ${ }^{4} \mathrm{O}$ efeito ‘subjetivo' prende-se com o fato de que a crise, em cada país, não é apenas económica; ela é uma crise existencial, experienciada individualmente, com efeitos profundos a nível da formação ou transformação da subjetividade e de percepção e

\begin{tabular}{|c|c|c|c|c|}
\hline $\begin{array}{l}4 \quad \text { Para } \\
\text { http://www.pordata.pt/Europ } \\
\text { 1798-214339 }\end{array}$ & $\begin{array}{l}\text { dados } \\
\text { Taxa+de }\end{array}$ & esempr & $\begin{array}{l}\text { recentes estatístic } \\
\text { o++dos+15+aos+64+anos++por }\end{array}$ & grupo+etário- \\
\hline Rovita Dialectus & Ano 4 & n. 11 & Agosto - Dezembro 2017 & p. $264-279$ \\
\hline
\end{tabular}


construção de 'nós' como grupo. Os refugiados, por isso, representam um duplo desconforto: por um lado, eles representam o 'outro' em termos de valores fundamentais. Oriundos de países não-democráticos, a maioria não reconhece necessária ou automaticamente a supremacia de valores liberais democráticos, típicos e específicos do ocidente. Por outro lado, eles representam o 'outro' em termos de possível competição que deve ser erradicada - competição por exemplo, para obter emprego. Por último, eles representam o 'outro' na medida em que obrigam a uma exposição cultural e diversidade étnica que desestabiliza os fundamentos já ténues da própria identidade cultural, nacional, mas também individual de cada um.

\section{As implicações}

Depois da Segunda Grande Guerra havia um certo desconforto para aqueles que queriam defender uma agenda de 'direita'. A direita havia sido temporariamente marginalizada; a memória ainda era recente e a geração nascida nos anos 30, 40 ou 50, ou até mais tarde, conheceu vítimas e sobreviventes do holocausto. Mas será que nós somos moralmente superiores em relação aos seres humanos da década de 1930 ou 1940? Será que nós estamos imunes às catástrofes produzidas por nós mesmos? Será que temos um instinto moral? Hitler pensava que não; o Holocausto começou com a ideia de que nenhum instinto humano é, de fato, moral; os seres humanos definem-se pela condição em que vivem, uma condição de permanente luta pela própria sobrevivência: o estado de natureza, afinal, não é erradicado pela política nem pelo pacto social. ${ }^{5}$ Em nome da segurança tudo se torna legítimo; já dizia Hobbes que em circunstâncias extraordinárias tudo é permitido. Mas o que constitui essas circunstâncias extraordinárias? Será preciso a erosão de um Estado com todas as instituições? Se pensarmos bem, essa foi a condição para as vitórias sucessivas de Hitler: o desmantelamento das instituições, a redução do cidadão a um corpo desprovido de direitos e de sentidos. O mesmo aconteceu e acontece na Síria, daí que todos os massacres aconteçam sem que ninguém possa, de fato, fazer nada. Os

\footnotetext{
${ }^{5}$ Ver o artigo de Timothy Snyder, historiador, intitulado "Hitler's world may not be so far away" em https://www.theguardian.com/world/2015/sep/16/hitlers-world-may-not-be-so-far-away, acesso a 28 de Maio de 2017.

\begin{tabular}{|l|l|l|l|l|}
\hline Q Povista Dialeatus & Ano 4 & n. 11 & Agosto - Dezembro 2017 & p. $264-279$ \\
\hline
\end{tabular}
}


direitos humanos mostram a sua hipocrisia, ou no mínimo, a sua impotência quando desligados dos direitos de cidadania. ${ }^{6}$

Quer o desafio econômico e político, quer o desafio humanitário de refugiados, representa o convite à elaboração de agendas políticas alternativas. Estas agendas partem de uma descrição do real. O que elas dizem (na França, na Áustria, na Holanda, no Reino Unido) existe. O perigo existe, porque o 'outro' existe. Mas o perigo não se resolve apenas eliminando o 'outro'. Se assim fosse, poderíamos fazer uma comparação mais direta com os anos 30 ou 40 do século passado. O desafio é diferente. É preciso eliminar o outro indiretamente. Como? Mostrando todas as limitações, problemas e contradições do modelo da democracia liberal representativa. Apelando à necessidade de reconstrução de uma identidade coletiva comum, onde cada um se espelhe de fato. Vejamos.

\section{Brexit}

A 23 de Junho de 2016 o Reino Unido passou por um referendum que teve um resultado chocante: $52 \%$ dos britânicos decidiu sair da União Europeia. Desta decisão, Inglaterra e o País de Gales tiveram a maioria para sair da U.E. (com 53,4\% e 52,5\% respetivamente) enquanto Escócia e Irlanda votaram para permanecer (com 38\% e $44,2 \%)^{7}$ Quais os argumentos decisivos para este resultado? Em primeiro lugar, o argumento de que a U.E. ameaça a soberania nacional. Em segundo lugar, que o voto pela saída é uma manifestação contra as burocracias europeias e requisitos de homogeneidade entre países, que impacta diretamente na produção de bens, sobretudo alimentares. Em terceiro lugar, o argumento de que U.E. cristaliza interesses corporativos tornando mais difícil qualquer mudança mais estrutural a nível nacional. No fundo este é o argumento que diz que, apesar de todos os países europeus serem democráticos, a U.E. não é democrática, mas sim, anti-democrática. Em quarto lugar, a crença de que U.E. é, ou melhor, era uma boa ideia, mas a política monetária do euro foi um desastre. Em quinto lugar, o argumento de que a U.E. facilita a imigração o que agrava uma série de problemas depois da crise financeira de 2008. Em sexto lugar, de que o Reino Unido consegue desenvolver uma política de imigração mais

\footnotetext{
${ }^{6}$ Esta posição foi amplamente defendida por Hannah Arendt.

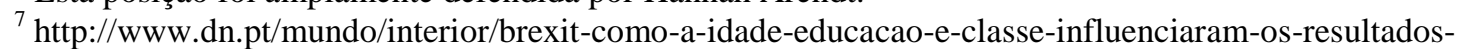
5246886.html. Acesso a 28 Maio de 2017.

\begin{tabular}{|l|l|l|l|l|}
\hline Qovista Dialectus & Ano 4 & n. 11 & Agosto - Dezembro 2017 & p. $264-279$ \\
\hline
\end{tabular}
}


eficaz que a U.E. E por último, a defesa de que o Reino Unido consegue maximizar o dinheiro para outros projetos, se não tiver que o enviar para a EU. ${ }^{8}$ Vários líderes partidários (Nigel Farage do UKIP ou Boris Johnson) protagonizaram este movimento de resistência e euro-cepticismo, apresentando o Brexit como solução para controlar as fronteiras, abandonar o mercado único e criar as suas próprias leis. ${ }^{9}$ Hoje, o plano de Brexit está intacto e em aparente movimento. Theresa May, a atual primeiraministra, incorporou a tarefa de representar a 'vontade do povo' e afirma que é preciso respeitar aquilo que os constituintes mais querem, a saber, um controle e uma redução da atual imigração. Claro que um olhar mais atento sobre os grupos demográficos mostra que $75 \%$ dos eleitores com idade igual ou inferior a 24 anos votou contra a saída, $56 \%$ com idades entre 25 e 49 anos, e só a partir dos 50 anos é que se dá uma inversão na escolha: 56\% a favor da saída, com idades entre os 50 e 64 anos, e $61 \%$ com idade superior aos 65 anos. ${ }^{10}$ Que partidos ascenderam com este referendum? Claramente o UKIP, mas o que se observa é que mais da metade dos apoiantes do partido Trabalhador que votaram para deixar a U.E. se associaram a novos partidos políticos: $9 \%$ mudou para os Tories, $8 \%$ para o UKIP e $25 \%$ ainda não se decidiu. ${ }^{11}$

\section{Le Pen}

Vejamos o que se passa em França. Marine Le Pen representa a nova cara da direita europeia. Líder do Front National, Marina Le Pen soube distinguir-se e afastar-se de seu pai, Jean Marie Le Pen. Se este representava a voz da direita tradicional do século XX, com pautas racistas, xenófobas, anti-imigração e antisemitas, definido pelo apelo a valores republicanos originais, Marine Le Pen percebeu que o desafio do século XXI é diferente: a direita não pode crescer baseada nos mesmos mitos - apelo ao medo, insegurança, identidade nacional - mesmo se estes podem continuar a existir. A direita do presente e do futuro representa a lucidez e a coragem de pronunciar um juízo político que se, por um lado, denuncia os perigos do

\footnotetext{
${ }^{8}$ http://www.vox.com/2016/6/22/11992106/brexit-arguments. Acesso a 29 de novembro de 2016.

${ }^{9} \mathrm{http}: / /$ www.ukip.org. Acesso a 29 de novembro de 2016.

${ }^{10} \mathrm{http} / / / \mathrm{www}$.politico.eu/article/britains-youth-voted-remain-leave-eu-brexit-referendum-stats/. Acesso a 30 de novembro de 2016 .

$11 \mathrm{http}: / / \mathrm{www}$. independent.co.uk/news/uk/politics/brexit-labour-party-poll-eu-vote-leave-memberslook-for-another-party-ukip-tories-latest-a7325581.html. Acesso a 30 de novembro de 2016.

\begin{tabular}{|c|l|l|l|l|}
\hline QRovista Dialectus & Ano 4 & n. 11 & Agosto - Dezembro 2017 & p. $264-279$ \\
\hline
\end{tabular}
}


politicamente correto, por outro, joga o mesmo jogo democrático para ampliar a sua base de apoio na sociedade. Marine Le Pen não defende tudo aquilo que nós, 'democratas', censuramos: os skin heads, os homofóbicos, os racistas; pelo contrário, ela rejeita qualquer contato com eles. O que ela faz, e tem feito desde a separação com o seu pai, é capitalizar nas deficiências do discurso democrático, alargando pautas e introduzindo questões que antes eram simplesmente negligenciadas. Marine Le Pen não é o vilão conhecido e familiar como o seu pai; e por isso também ela não é alvo fácil, nem para a esquerda nem para o centro. Ao contrário da direita do século XX que se definia por oposição declarada, por atos de discriminação e práticas de intolerância, Marine Le Pen é aparentemente democrata; inclusive, ela foi capaz de integrar pautas tradicionalmente de esquerda para reformular a sua base: pautas de defesa de direitos de minorias, de homossexuais e até de judeus. Le Pen sabe a expansão do seu partido não é apenas política nem ideológica; é uma expansão que depende da adesão contínua de franceses à sua proposta de como ver e interpretar o mundo, como identificar e resolver problemas. A ascensão da direita não tem só a ver com eleições. A ascensão da direita representa a guinada na forma como nós olhamos, vemos e projetamos o mundo. A introdução progressiva de certas pautas - como a da imigração - de repente, normalizou-se. A partir do momento em que se dá a normalização de pautas ou argumentos, cria-se o espaço para a redefinição de narrativas. O que era 'dominante' deixou de ser, abrindo-se para a sua própria reformulação a partir de uma perspectiva de direita. Qual foi então a estratégia que permitiu esta guinada? A introdução da pauta da imigração permitiu conciliar, por um lado, um compromisso democrático de tolerância e pluralismo, aceitando e defendendo grupos distintos; por outro lado, a objetivação de um inimigo comum: o Islã. Repare-se o que é feito sub-repticiamente: grupos diversos são convidados a olhar para algo agora postulado como exterior a si, e identificá-lo como problema comum. A partir do momento em que o 'Islã' é percebido como 'outro' comum a muitos, como inimigo comum a um pluralismo inicial, esses grupos passam por uma conversão de identidade: aquilo que os separava, agora os une; abre-se espaço para a reconstrução do 'povo' francês. O que permite à direita vencer as lutas ideológicas ou conquistar espaço político e simbólico não é o apelo a valores religiosos, como antes, mas sim o apelo a valores seculares, ditos democráticos. Observa-se que muitos grupos que nunca pensaram votar na direita (jovens, gays, mulheres, negros, judeus,

\begin{tabular}{|l|l|l|l|l|}
\hline Govista Dialectus & Ano 4 & n. 11 & Agosto - Dezembro 2017 & p. $264-279$ \\
\hline
\end{tabular}


feministas, proletários) abandonam a esquerda ou o centro-esquerda e cedem ao populismo radical.

Neste sentido, Marine Le Pen apresenta-se como a única e real representante dos ideais europeus e da identidade ocidental, a civilização judaico-cristã. O que Le Pen alcança é admirável: ela preenche o vacum deixado pelos projetos sociaisdemocratas; ela reconhece a angústia existencial dos seus co-cidadãos sem cair em preconceitos que se poderiam voltar contra ela; ela reinventa a importância da cidadania e do projeto de construção da república francesa para os franceses. Ela usa o fracasso da esquerda e do centro-esquerda como combustível para novas pautas. Le Pen atrai socialistas e até comunistas, diz ela. Embora evite a expressão 'estado social', Le Pen tem como princípio regulador a fraternidade, i.e., a ideia de que o estado deve dar as mínimas condições aos mais pobres.

Quais as implicações desta guinada, física, política e simbólica? A democracia só existe no confronto com o seu outro; mas o seu outro é sempre plural. Não há democracia sem pluralismo. O pluralismo gera dissenso acerca de quem, ou do que, constitui cada povo soberano. A democracia permite as lutas ideológicas e físicas também, as lutas de ocupação de poder, de governo, mas sobretudo, de narrativas, de reconstrução de imaginários coletivos. Por isso, o 'povo' é e não é necessariamente a mesma coisa; ele é prova do movimento dialético de sujeitos, de grupos, de histórias. Nascido e desenvolvido no ambiente democrático, o discurso de direita fortalece-se à custa do confronto com o outro; o dissenso alimenta-a e com ele explora os possíveis sentidos do 'povo soberano'; assiste-se à luta pela interpretação e atribuição de sentido não só para a democracia, mas para o país. E como atribuir sentido? Toda a atribuição de sentido implica escolha, toda a escolha implica rejeição de algo; neste caso, a conquista de nova identidade faz-se à custa da exclusão do 'outro'. O 'outro' existe, mas ele é também fabricado. E aqui entra o projeto de Le Pen e da extremadireita. Marine Le Pen sabe que o jogo é democrático e ela segue as regras. Mas essas regras são subvertidas de forma a introduzir elementos que obriguem a uma solução não-democrática. Porquê 'não democrática'? Porque a solução consiste na erradicação do problema, e sendo o problema o 'outro', a partir do momento em que o problema é resolvido, a democracia é também eliminada, ou, superada.

Apesar de Marine Le Pen não ter ganho as últimas eleições presidenciais na França, em Maio de 2017, os resultados foram históricos, alcançando 33,9\% dos

\begin{tabular}{|l|l|l|l|l|}
\hline Qovista Dialectus & Ano 4 & n. 11 & Agosto - Dezembro 2017 & p. $264-279$ \\
\hline
\end{tabular}


votos e tornando-se, com isso, o principal partido de oposição ao atual Presidente Macron. Este, embora considerado 'centrista' por muitos, define-se sobretudo pela ruptura que representa com o sistema partidário tradicional.

\section{Wilders}

Esta ascensão da extrema-direita é comum a quase todos os países europeus, inclusive aqueles que são tradicionalmente conhecidos pela tolerância ou pelo estado de bem-estar social. Na Holanda, por exemplo, o Partido Popular para a Liberdade e Democracia tornou-se percussor da nova extrema-direita. Hoje é a voz anti-imigração do país. Geert Wilders, fundador em 2006 do Partido da Liberdade, defende uma pauta que combina liberalismo económico com políticas anti-imigração. A sua influência tem aumentado na introdução de pautas que impactam diretamente na conceptualização de políticas públicas. Wilders combina o populismo com o apelo ao medo e ao ressentimento tradicionais, porém, é impossível compará-lo com Hitler afinal, também ele é um 'democrata'. Hoje, a questão da imigração de muçulmanos é a questão mais problemática na Holanda. A posição extremista de direita também não teve sucesso nas últimas eleições (Março de 2017), porém marca, como no caso francês, a presença desta visão de mundo no espectro político dito democrático.

$\mathrm{Na}$ Dinamarca a tendência é idêntica. O problema da imigração tem dominado o discurso político e o confronto entre ideologias. As esquerdas veem as suas conquistas passadas minimizadas e são condenadas publicamente pelo erro estratégico de terem abraçado os 'estrangeiros' à custa da proteção das 'classes'. O que se depreende desta breve análise é que a solidariedade, que é a base do sistema social da Escandinávia, erodiu.

\section{Trump}

Uma última análise deve ser introduzida, a saber, as últimas eleições presidenciais nos Estados Unidos e a vitória de Trump. No passado dia 9 de Novembro de 2016 Trump foi eleito presidente dos EUA. Enquanto muitos teóricos, filósofos, ativistas e pessoas de esquerda se mobilizam na denúncia desenfreada do que ele representa ou do perigo que traz para dentro de casa, ainda se vive numa certa

\begin{tabular}{|l|l|l|l|l|}
\hline Qovista Dialectus & Ano 4 & n. 11 & Agosto - Dezembro 2017 & p. $264-279$ \\
\hline
\end{tabular}


perplexidade, tentando compreender como isto aconteceu. Confesso que não fiquei surpreendida. Se observamos o movimento político dos últimos 16 anos, e isto para me referir a um período de tempo em que as minhas memórias pessoais são mais vivas, os EUA já eram um país cindido. Trump simplesmente veio trazer à tona o que muitos sabiam mas evitavam confrontar.

Para refletir acerca do que representa Trump eu queria dialogar com Umberto Eco e o seu texto "14 lições para identificar o neofascismo e o fascismo eterno", por um lado, e com Drucilla Cornell e Stephen Seely, e seu artigo recente intitulado "As sete teses sobre Trump". ${ }^{12}$ Sigamos as 7 teses avançadas por Cornell e Seely:

Tese 1. Trump é fascista e representa o 'fascismo'. Em que sentido devemos entender 'fascismo'? De acordo com Eco, uma das características do fascismo eterno é o culto da tradição. Falar de culto da tradição significa apelar a uma verdade eterna, primitiva e/ou quase esquecida, que o protagonista político agora quer recuperar. Ao abraçar este culto de tradição, estamos a rejeitar, quer queiramos quer não, a própria modernidade. A modernidade, com Habermas bem notou, é definida por uma característica específica e especial: a abertura à mudança. ${ }^{13}$ Embora fascistas, como nazistas, adorassem a tecnologia, essa tecnologia era apenas vista como um meio para reforçar o apelo à tradição, ao sangue, à terra. Ser contra a modernidade é ser contra o imperativo kantiano de 'Sapere Aude'. É recolher-se e projetar-se para dentro e para o passado. ${ }^{14}$ Trump parece ter esta característica; no seu discurso encontramos uma condenação ou censura a atos 'modernos' de expansão ou redefinição de si, enquanto sujeito e enquanto povo. O fascismo de Trump verifica-se na forma pela qual ele incarna o herói masculino, representando a promessa do restabelecimento de uma ordem perdida: e esse restabelecimento depende de um revival do nacionalismo. $\mathrm{O}$ apoio popular maciço torna-o um fascista e não apenas autocrata, como Cornell e Seely bem mostram.

Tese 2. Se Trump é fascista e se o fascismo nasce no seio da democracia, devemos combatê-lo com meios democráticos e expor a tentativa de usurpação e subversão do poder. A democracia revê-se no mito da 'soberania popular'. Desde a

\footnotetext{
${ }^{12}$ https://criticallegalthinking.com/2016/11/28/seven-theses-trump/. Acesso a 28 de novembro de 2016.

${ }^{13}$ Ver Habermas, J., Discurso Filosófico da Modernidade: Doze Lições, São Paulo: Martins Fontes, 2000.

http://operamundi.uol.com.br/conteudo/samuel/43281/umberto+eco+14+licoes+para+identificar+o+ne o-fascismo+e+o+fascismo+eterno.shtml. Acesso a 1 de dezembro de 2016.

\begin{tabular}{|l|l|l|l|l|}
\hline Q Povista Dialeatus & Ano 4 & n. 11 & Agosto - Dezembro 2017 & p. $264-279$ \\
\hline
\end{tabular}
}


Revolução Americana, passando pela Francesa, até aos dias de hoje, falar de democracia implica afirmar que o povo é soberano. Em que sentido devemos entender a sua soberania? Normalmente, a soberania popular passa pelo reconhecimento de que o voto tem um peso determinante e final. Porém, o sistema americano manifesta-se aqui na sua mais perfeita contradição: Hillary Clinton ganhou o voto popular com mais 2 milhões de votos. Com efeito, ela foi a candidata presidencial da história com mais votos desde sempre. Daí se seguiria logicamente que Hillary, e não Trump, seria a escolha do povo. Porém, o colégio eleitoral é a instituição que mais bem demonstra a desconfiança estrutural diante das massas. Este colégio eleitoral tem raízes elitistas e racistas, criado para limitar e contornar a vontade popular. A solução seria criar uma emenda constitucional que abolisse essa mesma instituição.

Tese 3. Devemos contrariar todas as tendências de normalização levadas a cabo pelos media, não só nos EUA mas no mundo. O aparente nihilismo de Trump não deve ser compreendido como compensação para o seu fascismo: o fato de Trump não parecer ter ideologias fixas ou definitivas acerca de nada, não significa que ele não leve a cabo as suas propostas radicais. Pelo contrário, Trump ganhou por causa dessas propostas que atacam os fundamentos da ordem democrática: a começar pelo pluralismo e pela própria lógica do reconhecimento. E isto é ampliado na tese seguinte.

Tese 4. O nihilismo de Trump é a base do seu fascismo. Na medida em que Trump não tem grandes crenças, ele torna-se ainda mais perigoso do que outros líderes. Marx disse que a história se repete: primeiro como tragédia, depois como farsa. Lembremo-nos de Nietzsche: o fascismo no início do século XX na Europa procurava restaurar os valores perdidos da Europa; a política de Hitler visava reconstruir o sentido da vida: mesmo que essa vida fosse agora delimitada a apenas alguns, de acordo com critérios étnicos, sexuais ou religiosos. Hoje, 71 anos depois do holocausto, mas com vários genocídios pelo meio, genocídios que têm menos atenção dos media porque são estrategicamente 'periféricos', nós, humanos, esquecemo-nos do horror, e porque nos esquecemos estamos novamente em condições de o repetir. $\mathrm{O}$ problema é que, tal como as crises do capitalismo que quando se repetem se acentuam e tornam mais fortes, criando problemas estruturais cada vez mais difíceis de superar, também as crises que hoje assistimos a nível político terão consequências físicas cada vez mais catastróficas. O fascismo, confrontado com a perda de valores e ideais

\begin{tabular}{|l|l|l|l|l|}
\hline Qovista Dialectus & Ano 4 & n. 11 & Agosto - Dezembro 2017 & p. $264-279$ \\
\hline
\end{tabular}


ocidentais, manifesta-se, novamente, como tentativa desesperada de combater o nihlismo em que aparentemente estamos submersos. O paradoxo de Trump é que ele é simultaneamente fascista e nihilista. Ou seja, por detrás do véu não encontraremos nada a não ser o próprio véu, ou por outras palavras, por detrás do fascismo como meio não encontraremos nada a não ser o fascismo como fim.

Tese 5. Porque Trump ganhou? Será o eleitorado estúpido, racista, dominado pelo medo, pela insegurança trazida ou reforçada pelo desemprego maciço? Não. A vitória de Trump representa o colapso da moral e da política, ou melhor, da política enquanto moral. O sonho americano, diz Cornell e Seely, sempre foi um sonho de supremacia do homem branco. A perda de segurança económica trouxe consigo um problema fundamental de identidade nacional; os perigos a essa identidade não são apenas a perda de emprego, nem o grupo restrito de bilionários, mas também a globalização, a imigração, os movimentos sociais, etc. Aqui, tal como na Europa, a esquerda é culpada pelas mesmas razões: ignorou as classes e foi assimilada, integrada pela política corporativa de centro. Por isso, depois da vitória de Trump o pais se abre de forma ainda mais flagrante para a violência e para a intolerância.

Tese 6. O que todos queremos? O que todos, individualmente, ansiamos? Ser, saber porque somos, escolher como somos e com quem somos; e isso passa por pertencer a algo maior do que nós mesmos. A vida não se resume aos números, à matemática, ao dinheiro que ganhamos. Qual o sentido da vida? É esta perda de sentido que Trump soube estrategicamente manipular. Se todos procuramos um sentido para a nossa vida, Trump foi aquele que se propôs a recuperar isso. Trump, o bilionário que se torna o herói popular, consegue criar pontes de identificação entre si e o cidadão comum. Dizer que Trump é um 'perdedor', um 'louco', um 'sem sentido', tudo aquilo que durante meses ouvimos os jornalistas dizer acerca dele, é apenas reforçar o cidadão comum, que se sente assim e se revê, curiosamente, neste novo candidato. Ao contrário de todos os políticos que são dominados pela ideologia castradora do politicamente correto, Trump quebra as fronteiras do dizível e indizível, do pensável e do impensável. Ele diz em voz alta o que muitos pensam em silêncio. E por isso, ele aparece como candidato honesto, apesar das mentiras.

Tese 7. Trump convida à superação do neoliberalismo. Esta superação pode ser feita de duas formas: ou apelando a um sentimento de coletividade ou de pertença nacional, atacando o individualismo atomizado e alienado das práticas neoliberais. A

\begin{tabular}{|l|l|l|l|l|}
\hline Q Rovista Dialectus & Ano 4 & n. 11 & Agosto - Dezembro 2017 & p. $264-279$ \\
\hline
\end{tabular}


segunda forma é recuperando aquilo que Tocqueville e John Stuart Mill nos disseram há mais de 150 anos: despotismo só pode ser compensado com liberdade política, com associativismo, com recuperação do significado ético profundo da própria atividade política: o significado de criar um mundo em comum. Um mundo feito por nós e para nós; um mundo onde não é possível nem desejável escapar da responsabilidade pessoal.

\section{Reflexões finais}

Os conflitos mundiais a que assistimos hoje, não podem ser resolvidos, apenas compensados ou contidos. Dizer que o racismo, a discriminação, a intolerância são o problema é escolher ignorar o real perigo. A ascensão de políticas mais conservadoras ou da própria extrema-direita não deve ser interpretada como déjà-vu, até porque muitos não viveram esse tempo, não têm essa memória, não conhecem a experiência dramática. Todos os discursos de extrema-direita, no Reino Unido, em França, na Holanda, Escandinávia, ou Áustria, Alemanha, Hungria, Estados Unidos, entre outros, fazem sentido. Não são discursos vazios; eles significam algo, algo para quem os ouve, para quem procura uma solução ou um conforto, ou até, um sentido, para a própria vida. A sociologia busca a solução para problemas sociais; a economia para problemas econômicos, a psicologia para problemas mentais, mas o que todas estas disciplinas esqueceram foi a teologia, ou melhor dizendo, a relação entre o imanente e o transcendente. Aqui entra a urgência da filosofia hoje. $O$ fato de nascermos condenados à esfera da imanência, isto é, à crença de que todos os problemas, todas as soluções, todas as condições são da última responsabilidade do ser humano, não é necessariamente mau em si mesmo. Mas ele pode tornar-se negativo, quando a responsabilidade individual não é internalizada, quando os homens e mulheres do mundo se sentem perdidos e/ou são forçados a uma condição de atomização involuntária, porque a própria vontade parece refém de uma lógica de mercado que os ultrapassa. Votar no Trump ou votar em Le Pen ou qualquer outro candidato mais de 'direita' não significa ser ignorante, vítima de falsa consciência ou estúpido. Votar em Trump ou Le Pen significa aderir a uma visão do mundo, escolher um lado da história, escolher um horizonte de significado que representa a esperança para cada

\begin{tabular}{|l|l|l|l|l|}
\hline Qevista Dialectus & Ano 4 & n. 11 & Agosto - Dezembro 2017 & p. 264 - 279 \\
\hline
\end{tabular}


indivíduo, nem que isso signifique a superação do mundo em que vivemos hoje. Talvez caminhemos para as pós-democracias. Afinal, a pós-verdade já chegou.

\section{Referências Bibliográficas:}

ARENDT, H., Sobre a Revolução. Tradução de Denise Bottmann. São Paulo: Companhia das Letras. 2009.

HABERMAS, J., Discurso Filosófico da Modernidade: Doze Lições. São Paulo: Martins Fontes, 2000.

NUNES DA COSTA, M. A Crise da Democracia. IN: ROSAS, João Cardoso (Org.), Manual de Filosofia Política, Coimbra: Almedina, 2013.

TOCQUEVIlle, A., Democracia na América. Vol. 1 e 2. São Paulo: Martins Fontes, 2014.

\section{Referências Online}

APPIAH, Kwame Anthony, There is no such thing as western civilization. In https://www.theguardian.com/world/2016/nov/09/western-civilisation-appiah-reith lecture. Acesso a 28 de Maio de 2017.

CORNELL, Drucilla, SEELY, S. Seven Thesis on Trump. In: https://criticallegalthinking.com/2016/11/28/seven-theses-trump/Acesso a 28 de Novembro de 2017.

ECO, Umberto. 14 lições para identificar o neofascismo e o fascismo eterno. In: http://operamundi.uol.com.br/conteudo/samuel/43281/umberto+eco+14+licoes+para+ identificar+o+neo-fascismo+e+o+fascismo+eterno.shtml. Acesso a 1 de Dezembro de 2016.

SNYDER, Timothy, Hitler's world may not be so far away. In: https://www.theguardian.com/world/2015/sep/16/hitlers-world-may-not-be-so-faraway. Acesso a 28 de Maio de 2017.

\begin{tabular}{|l|l|l|l|l|}
\hline Q Rovista Dialectus & Ano 4 & n. 11 & Agosto - Dezembro 2017 & p. $264-279$ \\
\hline
\end{tabular}

